\title{
SOFRIMENTO ESCOLAR COMO IMPEDIMENTO DA CONSTRUÇÃO DE CONHECIMENTO/SUBJETIVIDADE
}

\author{
Nize Maria Campos Pellanda*
}

\begin{abstract}
Desencantamento do mundo: em Descartes, ele se encarna no sujeito abstrato do puro pensamento de si - aquele que não tem dor a mitigar, nem esperanças a realizar. Tanto o pensamento platônico quanto o cartesiano, por razóes diversas, implicaram um universo, desenfeitiçado, demitizado, "sem qualidades", racional, No universo mítico e mágico, ao contrário, "nada é natural na natureza”, tudo é sagrado. O sagrado, o mágico será o verdadeiro antagonista que a ratio procura eliminar. (Olgária Matos)
\end{abstract}

RESUMO : A partir de reflexôes sobre as conseqüências da modernidade em termos de uma profunda fragmentação das dimensões da realidade como gênese de sofrimento dos alunos através de práticas pedagógicas contrárias às necessidades dos seres humanos, elaboramos a questão central de pesquisa: As práticas formalistas e fragmentadoras das dimensōes do fazer, do ser e do conhecer podem redundar em dor e sofrimento comprometendo o desenvolvimento integral dos alunos? Descrevemos os pressupostos teóricos oriundos do paradigma da complexidade e como eles sustentam o arcabouço lógico-teórico da investigação. Os referenciais teóricos mais importantes foram buscados na Teoria da Biologia da Cognição, desenvolvida por $\mathrm{H}$. Maturana e F. Varela, cujo eixo central é a questão da inseparabilidade entre construção do conhecimento e construção de sujeito.

Palavras-chave: Sofrimento. Autopoiesis. Cognição. Acoplamento estrutural.

Pós-doutora em Educação e professora do Departamento de Educação da Universidade de Santa Cruz do Sul (UNISC).E-mail: nizepe@uol.com.br 
SCHOOL SUFFERING AS AN OBSTACLE TO KNOWLEDGE/SUBJECTIVITY BUILDING

ABSTRACT: Reflections on the consequences of modernity, seen as a deep fragmentation of reality dimensions that makes students suffer because of pedagogical practices contrary to human needs, led us to main question of this research: can the formalist and fragmentizing practices of the dimensions of making, being and knowing cause pain and suffering that jeopardize the full development of students? We describe the theoretical assumptions derived from the complexity paradigm and how they support the logical-theoretical structure of investigation. The most import theoretical frameworks were drawn from the theory of the Biology of Cognition developed by H. Maturana and F. Verela, whose main thrust is the issue of the inseparability knowledge building and subject building

Key words: Suffering. Autopoiesis. Cognition. Structural coupling.

\section{Introdução}

$\mathcal{A}$ educação contemporânea, apesar de todos os louváveis esforços para torná-la instrumento de humanização, acabou por se constituir num conjunto de práticas alheias às necessidades dos seres humanos e, por esse motivo, dificultando o acoplamento com a realidade. Essas dificuldades trazem sofrimento aos sujeitos envolvidos nos processos educativos porque atingem o âmago do processo de construção do conhecimento entendido aqui como inseparável da ontogenia dos sujeitos.

A contundente afirmação que abre este texto não é uma frase de efeito ou palavras panfletárias, mas emerge de algumas pesquisas que têm mostrado o sofrimento dos estudantes decorrente de práticas de uma instituição social que foi se afastando gradativamente da vida. Nessa cisão educação e vida, as pessoas implicadas no processo não somente não encontram sentido para as suas vidas naquilo que estudam, como também suas necessidades orgânicas não ficam contempladas na escola tradicional. Os estudos, neste sentido, são muitos e reveladores de uma realidade dramática que está sendo expressa no sofrimento dos jovens na atualidade (Cukier, 1996; Pellanda, 1992; Bateson, 1991 e 1999; Oliveira, 1999 e 2004; Maturana, 1995). E mais, apesar de todo o avanço das ciências cognitivas, das neurociências e das pesquisas a 
elas associadas, a escola ocidental, de modo geral, respeitadas importantes exceções, continua desconhecendo ou simplesmente não usando nas suas práticas pedagógicas alguns princípios fundamentais que estão a emergir com as ciências da complexidade e que dizem respeito a questôes epistemológicas, ontogenéticas e neurofisiológicas principalmente.

Começamos por mostrar algumas razões históricas do fenômeno articulando esses elementos com os dados de uma pesquisa sobre sofrimento e educação que estão sendo analisados à luz dos pressupostos oriundos do Movimento da Auto-Organização. Essa denominação se deve ao epistemólogo francês Jean-Pierre Dupuy, que identificou similitudes lógicas em ciências complexas que emergiram ao final da primeira metade do século Xx e nos anos iniciais do período subseqüente. Assim, Dupuy identificou relações formais entre a termodinâmica de Ilya Prigogine, os estudos da Primeira e Segunda Cibernéticas desenvolvidos por N. Wiener e Heinz von Foerster, respectivamente, os trabalhos em Biologia de H. Maturana e F. Varela, bem como de Henri Atlan e as pesquisas antropológicas de René Girard. O eixo comum estabelecido por Dupuy foi o princípio da auto-organização (Dupuy, 1996). Esses estudos vão oferecer-nos o arcabouço teórico para a sustentação de nosso processo de pesquisa. Mais recentemente, encontramos os estudos de Clara da Costa Oliveira, da Universidade do Minho (Portugal), que focalizam na educação como processo auto-organizativo (Oliveira, 1999).

Para estudar os impactos cognitivo/afetivos desses acoplamentos, estamos desenvolvendo uma pesquisa em duas escolas da rede púbica do interior do Rio Grande do Sul. Nosso foco está nos processos educativos e, mais especificamente, na questão do sentido. Consideramos aqui sentido numa perspectiva ampliada, ou seja, ele é entendido nesse caso em sua acepção cognitiva complexa, que atinge uma gama de marcas que vão do sentido psíquico, mental até aquilo que Varela pensou como um sentido biológico para a ontogenia do ser humano tendo em vista o funcionamento dos humanos por meio da auto-organização (Weber, 2002).

Entendemos sentido como aquilo que emerge da ação humana e, portanto, como produção dos seres humanos no bojo de sua ação sobre a realidade. Nessa perspectiva, ele faz parte do processo de conhecimento, estando presente no acoplamento dos seres humanos com o seu meio. 
A partir das considerações feitas, colocamos nosso problema: As práticas formalistas e fragmentadoras das dimensões do fazer, do ser e do conhecer podem redundar em dor e sofrimento e, portanto, em impedimentos do desenvolvimento integral para os alunos das escolas que adotam práticas tradicionais?

Para perseguir esta questão, recorremos, então, a um conjunto de pressupostos que explicitaremos a seguir e fomos a campo ouvir alunos e professores. Na seqüência, traremos alguns dados da pesquisa em desenvolvimento para refletir ainda de forma provisória sobre eles à luz do referido quadro teórico.

\section{Complexidade, educação e vida}

Aprender a pensar: nossas escolas não têm a menor idéia do que isso significa. (F. Nietzsche)

A abordagem da realidade e do conhecimento na modernidade, com algumas exceções importantes, trabalhava com a idéia de estabilidade, fragmentação e objetividade. Ora, esses são pressupostos muito distantes da vida concreta de cada ser humano e, por esse motivo, a filosofia e a ciência afastaram-se muito da vida pulsante, das emoçôes etc. Com Nietzsche, fazendo "filosofia a martelo", começa um alerta sobre a petrificação dos conceitos e uma denúncia da perda de autonomia dos seres humanos. Esse pensador vai desconstruir a centralidade da racionalidade abrindo caminhos para que entrasse um pouco de ar na civilização. Ao criticar profundamente a separação vida e conhecimento ele vai tocar no âmago da modernidade e, com isso, ele vai ser um dos fundadores das vá rias correntes que a filosofia contemporânea viu surgir, como a fenomenologia, o existencialismo, o pragmatismo etc. (Nietzsche, 1983). E por aí ele ataca a educação que impede os jovens de serem autores e de se experimentarem.

Nietzsche vai realizar algo muito importante para a filosofia e para a ciência, que é colocar a linguagem como um elemento fundador do humano. Mais tarde, Wittgenstein iria resgatar isso de forma genial em sua filosofia da linguagem. Heidegger também seguiria por esse caminho da preocupação com o papel da linguagem no humano. $\mathrm{O}$ interessante é que tanto Nietzsche como Heidegger vão 
recolocar a questão já sugerida por Feuerbach, mas não respondida, sobre o que significa ser humano.

Nessa linhagem de estudiosos da importância da linguagem para o humano vai surgir Humberto Maturana. A partir de uma nova Biologia de inspiração cibernética, esse cientista traz novamente nas suas pesquisas a pergunta sobre o humano ao mostrar o funcionamento dos seres vivos (incluindo os humanos) em termos de uma inseparabilidade (exceto a observacional) ser/conhecer/falar/fazer.

Ele se pergunta então: "O que é o humano?” (Maturana, 1994, p. 242). Para responder a esta questão ele procura na linguagem e na amorosidade as respostas. E não faz isso especulando, como durante muito tempo se trataram as questões da cognição, mas a partir de rigorosos estudos empíricos. Diz ele, numa tentativa de resposta à questão colocada:

Os seres humanos se originam na história dos primatas bípedes a que pertencemos há pelo menos três milhôes de anos atrás com a origem da linguagem e no viver no entrelaçamento do linguajar e do emocionar que chamamos conversar. Nessa história, a emoção fundamental é o amor como domínio das ações que constituem o outro como legítimo outro na convivência. Como resultado dessa história, os seres humanos existem no entrecruzamento de muitas conversações. (Idem, ibid.)

Com essas reflexões, Maturana pratica uma abordagem complexa da Biologia. Ele afirma, então, que nós, seres humanos, somos seres lingüísticos, amorosos e, ao mesmo tempo determinados por certa estrutura biológica, ou seja, a linguagem, os laços amorosos e um funcionamento cognitivo autônomo constituem-nos como seres humanos, isto é: constituímo-nos como humanos quando criamos laços amorosos com linguagem articulada e quando ela, simultaneamente, desenvolve-se graças aos laços amorosos que vamos estabelecendo filo e ontogeneticamente.

Para explicar o funcionamento dos seres vivos, Humberto Maturana desenvolveu, juntamente com seu discípulo Francisco Varela, a Teoria da Biologia do Conhecer (Maturana \& Varela, 1980). Os conceitoseixo dessa teoria são autopoiesis e rede. Trata-se de um par complexo em que o primeiro remete para as questôes de auto-regulação do vivo como sistema fechado e o segundo, para a dimensão de conectividade quando os seres vivos se abrem para o exterior. 
Essa teoria nasce no movimento cibernético e, mais especificamente na Segunda Cibernética: esse sentido, a abordagem desses cientistas vai recorrer aos princípios cibernéticos da auto-organização, da recursividade e de uma lógica circular. A noção de sistema que funciona a partir desses princípios passa a ser a plicada aos fenômenos da vida. Isso começou a ser feito a partir da chegada de Heinz von Foerster ao grupo de ciberneticistas. Von Foerster teve um papel fundamental no desenvolvimento da biocibernética e muito influenciou os biólogos referidos. Ele é autor dos princípios da "ordem pelo ruído" e do pressuposto de que o organismo humano é fechado para informações e aberto para a troca de energia (von Foerster, 2003).

Foi por esse caminho que andaram Maturana e Varela, mostrando a questão da auto-organização e, por conseqüência, da autonomia, como elementos-chave no funcionamento dos seres vivos. Daí emerge com muita força a questão do sentido na medida em que cada ser humano precisa construir sua própria vida de forma autônoma e o que vem de fora serve apenas como perturbações para uma mobilização dos processos ontogênicos. Tanto do ponto de vista emocional como do ponto de vista fisiológico o ser é um inventor de si próprio. O biológico, portanto, é uma articulação de todos os processos, incluindo a comunitário-social.

$\mathrm{Na}$ senda da cibernética seguiu também o médico e biólogo francês Henri Atlan, que desenvolveu uma teoria biológica de tipo autoorganizativo (publicada um pouco antes da de Maturana e Varela ${ }^{1}$ ). Para articular nosso raciocínio na seqüência do parágrafo anterior, salientamos uma frase-chave de Atlan (1992, p. 123) que mostra os pressupostos centrais de sua teoria: complexidade, ruído e autonomia. Diz ele: “(...) é como se o nosso aparelho cognitivo fosse uma espécie de aparelho criador, mais uma vez, de uma ordem cada vez mais diferenciada, ou seja, de complexidade a partir do ruído". Para ele, a organização biológica humana é uma fábrica de sentido.

Do princípio de von Foerster "a ordem pelo ruído", Atlan vai elaborar sua teoria como "a complexificação pelo ruído". Por meio dessa teoria Atlan tenta dar conta não somente de processos evolutivos como, com base nisso, vai pensar a aprendizagem como complexificação pelo ruído, num processo auto-organizador a partir do caos outras palavras: como parte desse processo auto-organizativo de complexificação pelo 
ruído está a produção de sentido que emerge pela interpretação que cada sujeito dá ao novo e ao aleatório, por intermédio dessa interpretação. Quando esse processo fica bloqueado por fixação de conteúdos, os mecanismos auto-organizadores são bloqueados com danos para os sujeitos que aprendem que são impedidos de realizar feedbacks transformadores, caindo-se então em estados redundantes. O que fica trancado aí é a produção de diferença e sentido, motores da complexificação.

A contribuição da termodinâmica, com a releitura da Segunda Lei da Termodinâmica do século XIX, realizada por Ilya Prigogine, representou um impulso muito grande ao Movimento de Auto-Organização e para a compreensão do funcionamento dos processos da vida e da aprendizagem. Prigogine, com sua visão integradora da ciência, lança uma ponte entre as chamadas ciências "duras" e as ciências da vida e as humanas. Com a sua Teoria das Estruturas Dissipativas, ele ganha o Prêmio Nobel em 1997. Essa teoria vai ser decisiva na compreensão de muitos fenômenos da vida até então inexplicados. Na Segunda Lei da Termodinâmica, enunciada no século XIX, fica expressa a idéia de uma perda constante de energia no universo em direção a uma morte térmica, dado que a energia térmica não é totalmente transformável em outras formas de energia, tal como ocorre com as outras fontes energéticas. Prigogine vai rever essa lei à luz da complexidade e da autoorganização, mostrando que, para os sistemas vivos (longe do equilíbrio e que dissipam energia em decorrência da presença do princípio da auto-organização), há uma reversão da entropia e produção de neguentropia. Essas idéias se articulam com o princípio de von Foerster do fechamento do sistema, mostrando o trabalho interno deste e o papel da neguentropia como produtora de ordem. Os conceitos de entropia e neguentropia ajudam-nos aqui para pensar o sistema escolar em termos de perda de energia decorrente da ausência do trabalho autônomo e criador dos sistemas humanos (seres humanos) e da necessidade de reversão dessas perdas pela autonomia do sistema.

\section{Patologias da escola e sofrimento}

Os pressupostos complexos anteriormente descritos são ignorados pela escola. Não se trata de uma exigência de refinamento da formação dos educadores, que deveriam conhecer tudo o que se publica na vanguarda da ciência. O que ocorre é que, de forma instigante, 
encontramos os referidos pressupostos desde há muito expressos numa Filosofia Perene, bem como parte de uma sabedoria do senso comum. $\mathrm{O}$ aprender a viver no fluxo, a idéia de uma circularidade entre o que fizemos e o que nos acontece, bem como o papel das emoçóes e da intuição no conhecimento, são idéias muito antigas que foram sendo esquecidas pela cultura da modernidade, mas que sempre retornam nas pessoas sábias de todos os tempos. Mas permanece, é claro, a necessidade da formação dos educadores em termos de acompanhar o desenvolvimento científico. O que vemos em nosso país e também fora dele, pelo contrário, é uma preocupação em reforçar esse formalismo da educação separada do viver, como é o caso muito em voga hoje, por exemplo, do trabalho com as competências e outros similares que aparecem travestidos de inovaçôes pedagógicas a partir de descobertas científicas. Contudo, na verdade, constituem-se nas velhas práticas mecânicas que vêm com outras roupagens. O que fazem esses tipos de formação é afastar ainda mais o educador das necessidades vitais dos seus alunos. Porém, o que realmente está fazendo mais falta em tudo isso é um trabalho de percepção dos educadores em termos de uma escuta sensível das necessidades mais fundamentais dos seres humanos que são seus alunos.

O que parece estar acontecendo com os educadores é uma certa dificuldade de pensar sobre sua própria formação como alunos, tendo sucumbido a uma cultura que os mergulhou nas fragmentaçóes que herdamos da modernidade. Dessa forma, o que encontramos na cultura escolar atual atinge os alunos no seu processo de desenvolvimento, trazendo muito sofrimento a eles. Podemos destacar aqui alguns aspectos do processo ensino-aprendizagem que se constituem em verdadeiras patologias, comprometendo o acoplamento dos seres humanos entre si e com o meio no qual vivem, e, ainda, autopoieticamente falando, comprometendo a relação consigo mesmos.

Em primeiro lugar, trata-se de uma "despersonalização", para usar as palavras de von Foerster (1996). Isso marca a patologia de uma cultura que exclui a subjetividade da ciência, concebendo um "universo sem sujeito" (op. cit.). Trata-se, portanto, de uma prática esquizofrênica, no sentido de uma cisão entre quem aprende e o que se aprende. Usamos aqui o termo esquizofrênico a partir de suas origens gregas: esquizo = cortado e frenus $=$ inteligência . 
José Cukier, psicanalista argentino, tem se dedicado às conseqüências, em termos de enfermidades psíquicas, do que ele chama de "ensino defeituoso". Este seria marcado, principalmente, pela ausência de ternura no vínculo escolar, como ainda pela dissonância entre as necessidades do educando e as práticas institucionais. Para semantizar essa patologia ele criou o termo "didactogenia", ou seja, as doenças causadas pela didática (Cukier, 1996).

Clara Oliveira, estudiosa da temática da educação e dos processos auto-organizativos, chama atenção para a necessidade de pensarmos as práticas educativas na perspectiva da auto-organização. Pensando sob o ponto de vista do observador, o que é imprescindível, se considerarmos a questão da autonomia de cada ser como um sistema fechado para informações; ela diz o seguinte:

Quando pretendemos educar pessoas não podemos esquecer de que os objetivos que estipulamos representacionalmente nas interações que com elas empreendemos são objetivos que existem no nosso âmbito observacional, e não nos seus domínios fenomenológicos. É claro que ao educarmos seres humanos, também eles sistemas observacionais, podemos tratálos como operários do primeiro grupo. Só que ao querermos que um organismo observacional tenha por representação as de um outro organismo observacional, estamos a esquecer que as representaçóes observacionais se encontram dependentes (são conseqüência e causa) do funcionamento autopoiético de todo o restante organismo. Pretender que um organismo observacional pense pensando que um outro organismo observacional pensa, só pode ter dois resultados: 1) o organismo recusase organicamente a assim funcionar (e essa recusa vai ser também importante para a sua autopoiesis futura) ou 2) aceita observacionalmente a sua atuação em face de instruçôes exteriores. (Oliveira, 1999, p. 74)

Von Foerster, na seqüência de suas contribuições à Segunda Cibernética, fará uma distinção entre "máquinas triviais" e "máquinas nãotriviais" para deixar bem claro o rompimento das segundas com o behaviorismo que seria o caso das primeiras.

As máquinas triviais trabalham com regras fixas em termos do princípio do estímulo-resposta. As máquinas não-triviais, pelo contrário, são aquelas que possuem um dinâmico estado interno capaz de se automodificar de acordo com as perturbações de forma não-previsível e que apresentam novidades. Essas elaborações permitiriam mais tarde a 
von Foerster fazer ampliações de seu sistema de pensamento para pensar a educação.

Uma das marcas das práxis educacionais tradicionais é a trivialização do ensino. Essa atitude não é inócua porque toca em aspectos constituintes do humano, como a questão de formular problemas tal um mecanismo de autoconstituição e de automobilização. Von Foerster, falando de um ponto de vista cibernético, e os seres vivos são cibernéticos na medida em que se auto-regulam, discorre que o ensino tradicional se constitui num processo de trivialização ao criar todas as dificuldades para o exercício da autonomia dos alunos. Diz ele (1996, p. 184-185):

Fica bem claro que a maior parte de nossos esforços educativos instituídos está dirigida à trivialização das nossas crianças. Estou usando o termo "trivialização" tal como se usa na teoria dos autômatos, na qual uma máquina trivial se caracteriza por ter uma relação fixa entrada-saída (input/output), ao passo que em uma máquina não-trivial (máquina de Turing) a saída (output) está determinada pela entrada (input) e pelo seu estado interno. Considerando-se que nosso sistema educativo está orientado para gerar cidadãos predizíveis, seu objetivo é eliminar os estados internos perturbadores que gerem imprevisibilidade e novidade. Isso se torna claramente evidente no nosso método de avaliação, no qual somente se fazem perguntas para as quais as respostas são conhecidas (ou definidas) e devem ser memorizadas pelo estudante. Chamarei isso de "perguntas ilegítimas".

Não seria fascinante pensar em um sistema educacional que destrivialize aos seus estudantes, ensinando-lhes a fazer "perguntas legítimas", ou seja, perguntas para as quais as repostas são desconhecidas.

As perguntas legítimas seriam aquelas que mobilizam o estudante para construir conhecimento, construindo-se a si próprio. Em contrapartida, as perguntas ilegítimas seriam impeditivas de conhecer e de ser. Ora, isso tira do aluno a oportunidade do trabalho interno de busca de sentido para aquilo que interessa para a sua ontoepistemogênese. ${ }^{2}$ É esse trabalho interno do sistema, portanto, que é negado aos alunos. E sem essa internalidade não há autopoiesis, ou seja, autoconstrução.

Gregory Bateson, um dos membros mais representativos do Movimento Cibernético, também vai pensar a educação na perspectiva cibernética, considerando a ausência dos "padrões que conectam" como a negação do todo sistêmico e, por isso, deformadora. 
O que Bateson focaliza traz de volta, mais uma vez, os padrões de que estamos tratando aqui: a fragmentação profunda da cultura, que vivemos apontando mais especificamente para a questão da separação vida versus conhecimento.

Com esses elementos batesonianos nascidos no berço da cibernética, podemos pensar a escola ainda por meio do pressuposto de Double Bind (duplo vínculo) de Bateson (1999). Esse conceito foi elaborado por ele para servir às suas pesquisas antropológicas com populações fora do circuito ocidental, bem como com pessoas portadoras de esquizofrenia no Ocidente. No primeiro caso, ele observava relações familiares ambíguas em termos de dupla mensagem, que era passada aos sujeitos confundindo-os. O que os adultos esperavam em termos do comportamento das crianças não deveria corresponder à mensagem original. Ora, Bateson reconhecia aí uma causa de patologia. Contudo, de acordo com a postura cibernética desse cientista, um fato isolado de dupla mensagem não constituiria uma repercussão futura de patologia, mas sim um padrão que se repetiria. Ao se repetir esses padrões comportamentais, configurava-se uma determinada cultura que se autoconservava em termos de padrões que alimentavam os seres humanos atingidos por esses procedimentos. Trata-se de uma relação que implica um ato de violência contra os sujeitos do contexto e, por isso, implicaria também desamor. Isso poderia ser identificado ainda em nossa cultura no cotidiano de algumas famílias que são repressoras com os seus filhos, afirmando que tomam determinadas atitudes para o bem deles. Para Bateson, quando isso se estabelece profundamente na infância como um padrão familiar, é praticamente impossível para o indivíduo escapar dele. Esse padrão acaba por configurar uma distorção na comunicação, levando usualmente à esquizofrenia.

$\mathrm{Na}$ cultura moderna, configurada a partir das fragmentaçóes que temos apontado aqui, parece ter havido uma marca muito forte em termos de Double Bind. Essa característica está muito presente na escola e também em muitos outros diferentes espaços, como o trabalho, as rodas de amizade etc. Tudo parece girar em torno de ambigüidades: a hipocrisia social é um claro exemplo dessa cultura. As pessoas tratam muito bem sujeitos que encontram na sociedade e, longe deles, são críticas e pouco caridosas em relação a eles. Essa emergência patológica de uma cultura fragmentada pode ser um instrumento teórico muito importante para entendermos a cultura escolar. 
Um mecanismo fundamental do viver, para Maturana e Varela (1990), é o do acoplamento entre sujeito e meio, que eles chamam de acoplamento estrutural. Trata-se de um processo constituinte e recursivo dos seres humanos que funciona de forma integrada para cognição/subjetividade. Ora, a escola é justamente aquele ambiente que não facilita o acoplamento dos sujeitos por não oferecer condiçôes a partir das quais os seres humanos possam selecionar elementos que façam sentido para sua ontogenia (Oliveira, 1999).

\section{O fluxo da pesquisa e algumas emergências}

A coleta de dados dessa pesquisa está sendo realizada em turmas de $5^{\text {a }}$ série do ensino fundamental de duas escolas da rede estadual de ensino, do estado do Rio Grande do Sul, localizadas em duas cidades diferentes. Esses dados são coletados a partir de entrevistas semi-estruturadas e conversaçóes livres com as bolsistas da pesquisa. Também serão coletados dados de história de vida de dez educadoras. Não trataremos aqui desses últimos porque essas narrativas ainda não foram recolhidas. Trata-se de uma pesquisa em andamento, o que significa que não temos elementos conclusivos, mas o que será analisado neste momento são as emergências de um processo investigativo em trânsito.

A análise e a discussão dos dados estão sendo feitas a partir de alguns padrōes e marcadores. Não trabalhamos com categorias porque acreditamos que elas não são adequadas para lidar com uma realidade complexa e sempre em devir. As categorias essencializam os fenômenos e isso compromete o tipo de abordagem que estamos querendo atingir.

Uma primeira dimensão dos dados é pensada em termos de "padróes que conectam", tal como foram concebidos por Gregory Bateson no sentido de uma realidade que vai se configurando por meio da repetição de padrōes (Bateson, 1991).

Uma segunda dimensão de tratamento dos dados é a dos marcadores que correspondem aos pressupostos teóricos mais importantes do quadro teórico usado e que vão sendo aplicados à realidade emergente, em termos de princípios vivos que vão configurando a realidade desses sujeitos.

Assim, o que percebemos com mais intensidade de padrões que se repetem nas respostas são aqueles referentes ao sofrimento dos 
sujeitos na escola. Pelas respostas apresentadas vamos inferindo que o sofrimento está relacionado com a falta de sentido do que aprendem, com a negação do falar, com a dupla mensagem da escola, com a fragmentação aprendizagem/vida, com a ausência do prazer das tarefas escolares, com o medo das provas, com o impedimento da autoria e com a naturalização de uma escola em que o prazer e o sentido estão ausentes. A falta de sentido está relacionada com todos esses padrões, mas podemos focar o maior problema em torno da negação do conversar, pois sem linguagem não podemos construir realidade e conhecimento e, portanto, sentido.

No conjunto de respostas, não aparecem elementos que mostram a abertura para construção de sentido. O que aparece sempre é a dicotomia mal-estar em sala de aula e o prazer do recreio ou de outros espaços de convivência e conversação como o refeitório, por exemplo. É muito intensa a expressão da necessidade de falar e como essa necessidade é negada na escola. Aparece ainda a cisão entre o discurso oficial da escola (expresso no Plano Político-Pedagógico e no $s$ discursos dos dirigentes) e o que realmente "rola" no processo educativo. Bateson, como vimos anteriormente, chama isso de Double Bind. Isso cria um padrão de distorção na comunicação e de fragmentação que atinge profundamente o desenvolvimento sadio das crianças. Esses elementos são expressos nas respostas da seguinte forma: perguntados sobre se gostam da escola, elas respondem, na maioria das vezes, que a escola é importante para o futuro, para se arrumar um emprego etc. Ou seja, as respostas são formais, repetem clichês que são ouvidos em casa. Mas o interessante é que, à medida que vão sentindo mais confiança com as entrevistadoras, vão deixando sair alguns desabafos que contradizem certas respostas formais. As entrevistadoras (bolsistas de Iniciação Científica) são consideradas observadoras implicadas e parte do sistema. A partir desse pressuposto, ao criar recursividade das conversações e mútuas provocações, elas vão constituindo um ambiente onde os sujeitos vão se expressando/constituindo (Pellanda, 2003).

O mais preocupante em tudo isso é a naturalização dessas práticas pelos alunos. Perguntados sobre se tivessem oportunidade de inventar uma escola de seu jeito, as respostas se dividem: uns dizem que não dá para ser diferente e outros pensam apenas nos espaços de prazer (reforma do ambiente do recreio, do refeitório e menos brigas entre os colegas). Alguns pensam numa escola "sem provas" e onde se possa 
falar e dar risadas. Bateson chama a atenção para a ausência de vida na escola. A reflexão abaixo é dramática mas, se formos pensar no que ocorre no cotidiano escolar, corresponde às palavras desse cientista:

Por acaso os professores sabem que levam consigo o beijo da morte, que tornam insípido tudo quanto tocam, e então se negam sabiamente a tocar ou ensinar qualquer coisa que tenha importância para a vida real? Ou não será que portam o beijo da morte porque não se atrevem a ensinar nada de importância para a vida real? O que se passa? (Bateson, 1991, p. 7)

As respostas das crianças apontam para essa direção.

Para Atlan (1992, p. 124), as patologias da escola estariam ligadas à negação da interpretação dos conteúdos pelos sujeitos e à exigência de "colar-se à realidade", o que, obviamente, pelos critérios que estamos considerando, é antinatural, pois não existe uma realidade objetiva independente da ação do sujeito que conhece. A reposta de um aluno entrevistado ilustra o que foi dito: "Se tu é legal com eles (os professores), eles vão ser legais com nós, sabe. É só fazer o que pedem...”.

Com base nesses padrōes, selecionamos os marcadores para análise. São eles a autopoiesis (o processo auto-organizativo de cada sujeito), a linguagem como constituinte do humano, a dimensão rede do ser humano, incluindo aqui a questão da amorosidade, e o acoplamento estrutural e as noções de entropia/neguentropia. Esses elementos são considerados aqui necessidades fundamentais para o viver humano, como constituintes de sujeito, de conhecimento e de realidade e não meros complementos. A negação deles pela escola constitui-se em violência aos seres humanos, na medida em que impede o livre fluir do processo de viver e, portanto, o próprio processo de acoplamento estrutural.

A aprendizagem é um fenômeno biológico e comunicacional. Isso quer dizer que a sobrevivência é uma questão de acoplamento com a realidade e a linguagem é um fator fundamental. " $\mathrm{Na}$ medida em que os seres humanos são sistemas autopoiéticos, todas as suas atividades como organismos sociais devem satisfazer sua autopoiesis" (Maturana \& Varela, 1980, p. XXVI).

Os seres humanos constroem-se na linguagem, tanto na sua dimensão ontogênica como cognitiva. Portanto, o processo autopoiético (autoconstrução) dá-se por meio de um processo de linguajar-emocionar. 
A negação dessa característica básica do viver na escola é profundamente grave em termos autopoiéticos, pois o que está se negando, sistematicamente, é a oportunidade de as crianças se desenvolverem com todas as condiçôes de que necessitam para tal. E o que vemos é uma incidência muito grande de respostas das crianças que indicam não somente a proibição do conversar, mas como isso vem acompanhado de sofrimento. Nas palavras de um entrevistado encontramos as seguintes respostas às perguntas de uma das entrevistadoras:

E: Tem alguma coisa na escola que te causa aborrecimento?

A: Não. É, pensando bem, algumas professoras.

E: Me conta o que elas fazem que te deixa aborrecido.

A: Ah! São uma chatice.

$\mathrm{E}:$ Que chatice que elas fazem?

A: Algumas já pegaram no meu pé.

$\mathrm{E}:$ Como assim?

A: Antes eu incomodava, agora eu parei, mas qualquer coisa que acontece dentro da sala elas já ficam olhando para mim e achando que eu sou o culpado. Agora eu não incomodo mais as professoras. Quer dizer, só um pouquinho.

E: O que é o incomodar a professora?

A: Conversar com os colegas.

$\mathrm{E}:$ E tu conversa na aula?

A: Só um pouquinho. ${ }^{3}$

E: É um pouquinho, ou um pouquinho bastante?

A: É para bastante.

E: Sobre o que tu conversa em sala de aula?

A: Converso sobre tudo, a maioria das vezes é sobre outras coisas.

Respostas como estas são a tônica das entrevistas. A necessidade de conversar é constitutiva do humano, ao passo que a escola está noutro registro: o da transmissão, o da correspondência simétrica entre o pensamento e a realidade, o da homogeneização, o do não-reconhecimento da autonomia de seres que precisam conversar para se construírem na emoção. Maturana (1999, p. 47) nos diz que "Tudo o que nós, 
seres humanos, o fazemos como tal, o fazemos nas conversações. E aquilo que não fazemos nas conversações, de fato, não o fazemos como seres humanos".

Outro elemento é a amorosidade. As crianças precisam ter a sensação de que são vistas e, ao mesmo tempo, precisam participar das redes de amizade da escola porque são seres sociais. Maturana fala da "dor de não ser visto": ${ }^{4} \mathrm{Um}$ dos alunos comenta sobre os seus professores: "não dão bola para a gente e xingam a gente ainda. Imagina só". Outros insistem na necessidade de contar coisas para os amigos.

(...) as crianças não aprendem coisas, elas se transformam na convivência com o professor ou professora. Vê-se que as crianças se transformam de uma ou outra maneira. Se a situação os nega, então aprendem esse viver, no qual são negados, com todas as características de sofrimento que isso traz consigo. Encontramos mais tarde com meninos de 16 anos que não "estão nem aî", porque sua vida não tem sentido, porque nem sequer sabem respeitar a si mesmos. (Maturana, 1995, p. 17)

Com esses padrões vão se formando seres humanos que, ao não encontrar sentido no que fazem na escola, não encontram sentido em si mesmos. Nessas condições, não desenvolvem autonomia e auto-estima e, por isso, ao não conseguir dizer sim a si mesmos, afirmando-se a si próprios, não podem dizer não às drogas (op. cit.). E é neste sentido também que podemos observar um padrão que se estende pelo mundo inteiro: as paredes de prédios, monumentos e pontes estão crivadas de pichações: os jovens estão gritando para dizer algo que não conseguem dizer a partir das recursivas negaçôes de uma cultura na qual a escola tem uma forte influência.

O sofrimento com as provas é evidente e aparece na maioria das respostas. Aqui, há o grande equívoco da metafísica cartesiana que nos passou a idéia de que o outro existe como um objeto concreto fora de nós. $\mathrm{O}$ que ocorre é que somos sistemas observantes, que não podemos saber o que se passa noutro sistema autônomo. Ao julgarmos o que o aluno sabe ou não sabe, estamos fazendo de acordo com os nossos próprios padrões de observadores e que não correspondem à realidade do outro. Essa realidade e a cognição aí implicada dependem da ação de cada um em relação ao seu meio. E aí não avaliamos as operações mentais e corporais que um sujeito constrói para se acoplar à realidade, não avaliamos nem mesmo a pobreza do ambiente cheio de limitaçôes que 
nós educadores oferecemos aos alunos. O que avaliamos é a correspondência simétrica entre o pensamento e um mundo supostamente existente fora dos sujeitos. E esse mundo não existe, é puro delírio. Nossa educação é delirante na medida em que não existe cognição sem a ação efetiva de um sujeito sobre a realidade.

Com isso, alimentamos recursivamente um padrão de negação do outro, de enfraquecimento da auto-estima, porque inviabilizamos a invenção sem a qual não existe cognição nem sujeito. $O$ sofrimento que se segue a esse processo não somente é inevitável como devastador.

Sofrimento ou invenção? A bifurcação necessária

(...) cada vez que negamos nossas características biológicas de seres recoletores e compartidores de ali mentos, que formam sistemas sociais fundados no prazer da convivência e não na competição, geramos neurose. (H. Maturana)

Este não é um relatório final de pesquisa, mas apenas um artigo que organiza as idéias de um processo em devir. Por esse motivo, os dados recolhidos e as reflexões sobre eles tiveram muito mais o caráter de pequenos flashes. Feito este esclarecimento, partimos para uma rápida sistematização do que aqui foi tratado.

A noção da cognição como um fenômeno biológico e inseparável da vida esteve no centro de nossas preocupações neste texto. $\mathrm{O}$ que se seguiu como conseqüência foi a questão da produção de sentido e as implicações de sua negação pela escola. Nessa perspectiva, consideramos a organização biológica como processo de produção de sentido para o viver constituindo a ontogenia desse organismo. É importante que se esclareça aqui que a aprendizagem é inerente ao viver e, portanto, ela acontece independente da escola. Mas, em contrapartida, como somos seres de terceira ordem (vivemos em comunidade), a importância da dimensão social é crucial no acoplamento estrutural. E aí entra a escola com a negação de um ambiente que favoreça as relações sociais produtoras por meio das conversaçôes e da amorosidade. Isso reverte contra o sujeito, pois dificulta sua interação com o seu ambiente.

Outro nível deste impedimento de interação seria o que diz respeito às questóes do próprio processo de conhecer/viver no sentido da 
complexificação pelo ruído. O trabalho interno de organização a partir do ruído é fundamental para que haja desenvolvimento, ou seja, complexificação. O objetivo da escola, diferentemente do princípio foersteriano da "ordem pelo ruído", parece ser o da "ordem pela ordem”. Sem ruído, isto é, perturbação, que dispare os processos cognitivos não há cognição/sujeito, porque não há construção de autonomia, gênese dos processos de auto-organização, e, portanto, de autopoiesis. Não pode haver sendas a serem selecionadas para os sujeitos palmilharem. Por isso eles vão perdendo aos poucos a capacidade de iniciativa e invenção, sentido fundamental do viver.

É preciso escolher entre o modelo atual da escola, profundamente arraigado no âmago de nossa cultura e produtor de sofrimento, e um modelo que seja capilar com o processo de viver. Essa seria uma escola como lembra Larrosa (2005, p. 45), ao falar de Nietzsche: "Chega a ser o que és! Talvez a arte da educação não seja outra senão a arte de fazer com que cada um torne em si mesmo, até sua própria altura, até o melhor de suas possibilidades".

Recebido em maio de 2008 e aprovado em outubro de 2008.

\section{Notas}

1. O nome da obra de Atlan, publicada em 1971, é Organisation biologique et théorie de l'information.

2. Ontoepistemogênese é um conceito criado pelo grupo de pesquisa GAIA (Grupo de Ações e Investigações Autopoiéticas) da UNISC, que investiga, numa perspectiva transdisciplinar, as questôes da inseparabilidade da construção do ser e do conhecer.

3. Nesse momento, o menino faz um gesto com a mão, demonstrando um pouquinho, e ao mesmo tempo procura encolher-se ficando atrás do gesto.

4. Comentário de Maturana numa palestra em maio de 2006, em Porto Alegre, num evento da ONG Parceiros Voluntários.

\section{Referências}

ATLAN, H. Entre o cristal e a fumaça. Rio de Janeiro: Zahar, 1992.

BATESON, G. Epiritu y naturaleza. Buenos Aires: Amorrotu, 1991.

BATESON, G. Steps to an ecology of mind. Chicago: University of Chicago, 1999. 
CUKIER, J. A educação escolar: agente de mudança psíquica positiva ou agente didaticopatogenizante? In: Pellanda, N. M. C.; Pellanda, L. E. Psicanálise hoje: uma revolução do olhar. Petrópolis: Vozes, 1996.

DUPUY, J-P. Nas origens das ciências cognitivas. São Paulo: UNESP, 1996.

LARROSA, J. Nietzsche e a educação. 2. ed. Belo Horizonte: Autêntica, 2005 .

MATURANA, H.; VARELA, F. Autopoiesis and cognition. London: Reidel, 1980.

MATURANA, H.; VARELA, F. El arbol del conocimiento. Santiago: Universitária, 1990.

MATURANA, H. Uma nova concepção de aprendizagem. Dois Pontos, Belo Horizonte, v. 2, n. 15, p. 28-35, 1993.

MATURANA, H. El sentido de lo humano. Santiago: Dolmen, 1994.

MATURANA, H. La educación: un ejercicio de humanidad. Revista de Educación, Santiago, n. 228, sept. 1995.

MATURANA, H. Transformaciones. Santiago: Dolmen, 1999.

MATURANA, H.; PORKSEN, B. Del ser al hacer. Santiago: J.C. Saez, 2004.

NIETZSCHE, F. Nietzsche. São Paulo: Abril, 1983. (Os pensadores).

NÓVOA, A. Os professores e as histórias da sua vida. In: NóvoA, A. (Org.). Vidas de professores. Porto: Porto, 1992.

OLIVEIRA, C. A educação como processo auto-organizativo. Lisboa: Instituto Piaget, 1999.

OLIVEIRA, C. Auto-organização, educação e saúde. Coimbra: Ariadne, 2004.

PELLANDA, N.M.C. Escola e produção de subjetividade. 1992. Tese (Doutorado) - Programa de Pós-Graduação em Educação, Universidade Federal do Rio Grande do Sul, Porto Alegre. 
PELLANDA, N.M.C. Conversaçôes: modelo cibernético de construção de conhecimento/ realidade. Educação \& Sociedade, Campinas, v. 24, n. 85, p. 1377-1388, set./dez. 2003.

PIAGET, J. Epistemologia genética. São Paulo: Abril, 1983.

VON FOERSTER, H. Las semillas de la cibernética: obras escogidas. Barcelona: GEDISA, 1996.

VON FOERSTER, H. Understanding understanding. New York: Springer, 2003.

WEBER, A. The "surplus of meaning". Biosemiotic aspects in Francisco Varelas's philosophy of cognition. Cybernetics \& Human Knowing, Copenhagen, v. 9, n. 2, p. 11-31, 2002. 